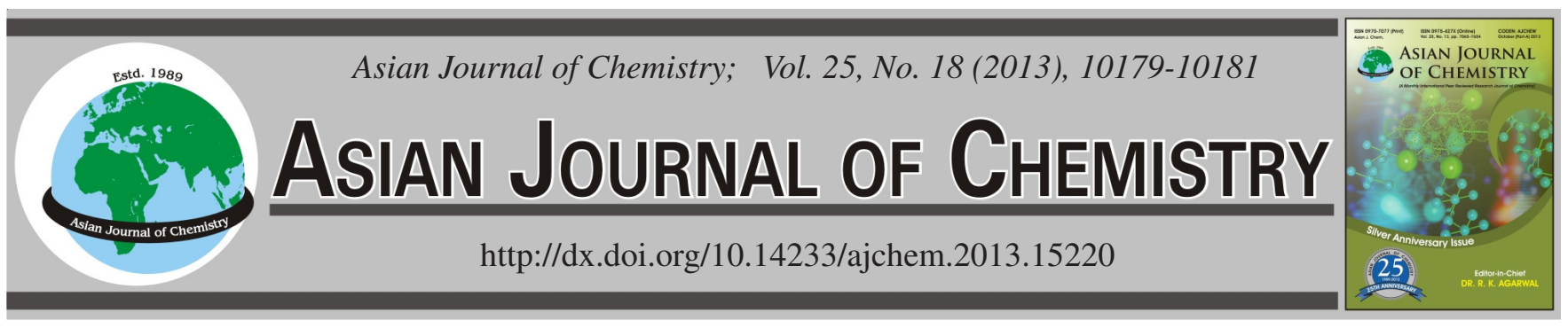

\title{
Determination of 2-Keto-L-gulonic Acid in Fermented Broth by Flow Injection Chemiluminescence Using Potassium Permanganate-Rhodamine B System
}

\author{
Xinli Lu ${ }^{1}$, Jing Feng ${ }^{2}$, Jujuan Zhang ${ }^{3}$, Suliang Chen $^{1}$, Yuqi Zhang ${ }^{1}$ and Hongru ZhaO ${ }^{1, *}$
}

${ }^{1}$ Institute of STD/AIDS Prevention and Control, Hebei Center for Desease Prevention and Control, Shijiazhuang 050021, P.R. China
${ }^{2}$ Hebei College of Chemical \& Pharmaceutical Vocational Technology, Shijiazhuang 050026, P.R. China
${ }^{3}$ Department of Finance and Economics, Shijiazhuang Vocational College of Finance and Economics, Shijiazhuang 050051, P.R. China

*Corresponding author: E-mail: 1xlii2009@163.com

(Received: 28 January 2013;

Accepted: 11 November 2013)

AJC-14361

\begin{abstract}
In this paper, a flow injection-chemiluminescence (FI-CL) was presented for the determination of 2-keto-L-gulonic acid in fermented broth. This method was based on enhance effect of 2-keto-L-gulonic acid on the chemiluminescence reaction between rhodamine B and potassium permanganate in acid medium. The optimized experimental conditions were evaluated. Under optimum conditions, calibration curve over the range of $0.2-60 \mathrm{mg} \mathrm{L}^{-1}$ was obtained. The detection limit of this method was $0.04 \mathrm{mg} \mathrm{L}^{-1}$. The relative standard deviation was $3.7 \%$ for $2.0 \mathrm{mg} \mathrm{L}^{-1}$ 2-keto-L-gulonic acid. The method validation has been compared versus HPLC method for determination of $2-$ keto-L-gulonic acid in fermented broth.
\end{abstract}

Key Words: 2-Keto-L-gulonic acid, Flow injection, Chemiluminescence, Potassium permanganate, Rhodamine B.

\section{INTRODUCTION}

Vitamin $\mathrm{C}$ is a kind of essential vitamin and antioxidant in human body and it can be widely used in the medical and food industry. In the commercial production of vitamin, only 2-keto-L-gulonic acid (2-KLG) is a key intermediate ${ }^{1}$. The most popular process for synthesizing 2-keto-L-gulonic acid is the Reichstein's method, in which glucose is transformed into 2-keto-L-gulonic acid through five chemical steps ${ }^{2}$. Since Gray's description of microbial method for the conversion of L-sorbose to 2-keto-L-gulonic acid, the microbial method has become attractive and gradually replaced the chemical method for lower industrial cost and less ecological problems " . 2,5Diketo-D-gluconic acid (2,5-DKG) pathway" is one of the most commercially promising methods for microbial production of 2-keto-L-gulonic acid, during the course of preparing 2-keto-L-gulonic acid, 2-keto-D-gluconic acid (2-KDG), the stereoisomer of 2-keto-L-gulonic acid might be accumulated simultaneously with 2-keto-L-gulonic acid from other organic acids in the fermentation broth (Fig. 1) ${ }^{4}$. Therefore, determination of 2-keto-L-gulonic acid in fermentation broth was very important in industrial production and scientific research of vitamin $\mathrm{C}$.

Methods of analysis for 2-keto-L-gulonic acid were grouped into microbial fermentation $(\mathrm{MF})^{5}$, capillary zone electrophoresis $(\mathrm{CZE})^{6}$, high-performance liquid chromatographic ${ }^{7,8}$. Although

\section{D-glucose}

$$
2 \text { days } \downarrow \text { (Erwinia sp.) SCB } 247
$$

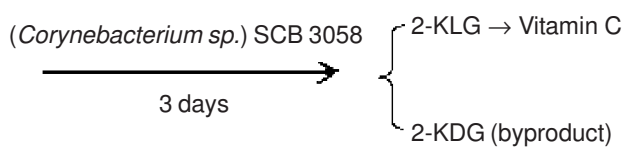

Fig. 1. Simple sketch about the transformation of glucose to vitamin C

the microbial fermentation was the most commonly used method, it was time-consuming were requires great care and skill. HPLC and CZE methods had the advantage of separating and quantifying different forms of 2-keto-L-gulonic acid and minimum interference from enzymes, but they involve set-up costs, a complex extraction and a purification procedure. Chemiluminescence (CL) is a powerful analytical technique that has excellent sensitivity, wide linear dynamic range and requires relatively simple and inexpensive instrumentation. It has attracted considerable attention in a number of fields such as clinical research, biotechnology, pharmacology, environmental chemistry and food analysis ${ }^{9-11}$. However there were few reports for the determination of 2-keto-L-gulonic acid based on chemiluminescence analysis system. 
In this study, we found that a strong chemiluminescence signal was given out when a trace amount of 2-keto-L-gulonic acid was added to rhodamine $\mathrm{B}$ and potassium permanganate in acid mixed solution and the chemiluminescence intensity was dependent on 2-keto-L-gulonic acid concentration. Based on this phenomenon, a new, rapid, simple, sensitive and inexpensive method was proposed to determine 2-keto-L-gulonic acid in fermented broth. It has more widely linear range and much lower detection limit. The method has been applied to the determination of studied 2-keto-L-gulonic acid in fermented broth with a satisfied result.

\section{EXPERIMENTAL}

2-Keto-L-gulonic acid (2-KLG), 2-keto-D-gluconic acid (2-KDG), 2,5-diketo-D-gluconic acid (2,5-DKG) were obtained from Sigma-Aldrich (St. Louis, Mo, USA). Rhodamine B and potassium permanganate were obtained from Beijing Chemical Reagent Company (Beijing, China). $\mathrm{HCl}, \mathrm{HNO}_{3}, \mathrm{H}_{2} \mathrm{SO}_{4}, \mathrm{H}_{3} \mathrm{PO}_{4}$, acetic acid and other reagents were all of analytical grades. The fermentation broth was kindly provided by North China Pharmaceutical Group Corp. All the above reagents were of analytical grade and used as received without further purification. Double-distilled water was used as carrier and for the preparation of solutions. The diluted working solutions were prepared and used freshly and daily.

Flow injection chemiluminescence was performed with an IFFL-D flow injection chemiluminescence analysis system (Xi' an Ruike Electronic equipment Corporate, Xi'an, China). The schematic diagram of the FI-CL analyzer is shown in Fig. 2. It consisted of 2 peristaltic pumps (working at a constant flow rate of $25 \mathrm{rpm}$ ). One channel was used to carry $\mathrm{H}_{2} \mathrm{SO}_{4}$ and Rhodamine B solution, the other channel was used to carry the $\mathrm{KMnO}_{4}$ solution, sample solutions and water were then injected from a sample valve. The enhanced chemiluminescence signals were produced immediately and were recorded. The flow cell was a $10 \mathrm{~cm}$-long spiral glass tubing ( $2 \mathrm{~mm}$ i.d.) and the distance between injection valve and flow cell was $15 \mathrm{~cm}$. The comparative test carried out by an Agilent 1200 series HPLC.

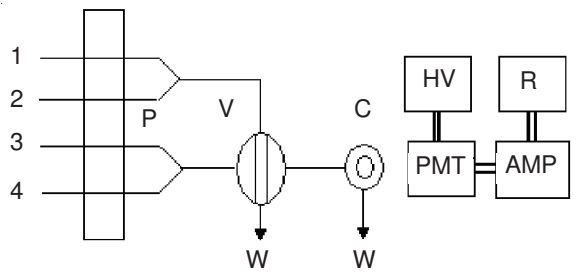

Fig. 2. Schematic of flow injection chemiluminescence analysis. 1. Rhodamine B solution 2. $\mathrm{KMnO}_{4}$ solution 3. carrier flow; 4. 2keto-L-gulonic acid; C. Flow cell V. Injection valve W. Waste solution PMT. photomultiplier tube; AMP. amplifier; HV. high voltage; $\mathrm{R}$. recorder

Preparation of standard solutions: The standard stock solution $\left(10 \mathrm{mg} \mathrm{mL}^{-1}\right)$ was prepared by dissolving $50 \mathrm{mg}$ 2-keto-L-gulonic acid in a $50 \mathrm{~mL}$ volumetric flask and make up to volume with water. A series of standard solutions were prepared by quantitatively transferring suitable stock solution to $25 \mathrm{~mL}$ volumetric flasks and made up to the volume with water.
Preparation of sample solutions: The composition of the fermentation broth was very complex, which not only strongly influenced the separation of tested components, but also would damage the chromatographic column to some degree. According to the experiences and related references ${ }^{12}$, the fermentation broth provided was taken and mixed with $\mathrm{ZnSO}_{4}\left(72.0 \mathrm{mg} \mathrm{mL}^{-1}\right)$ and $\mathrm{K}_{4}\left[\mathrm{Fe}(\mathrm{CN})_{6}\right] \cdot 3 \mathrm{H}_{2} \mathrm{O}\left(36.0 \mathrm{mg} \mathrm{mL}^{-1}\right)$ according to the proportion of $1: 1: 1(\mathrm{v} / \mathrm{v} / \mathrm{v})$ and centrifugal precipitation for $10 \mathrm{~min}$ by $13000 \mathrm{rpm}$. Then the above clear solution was filtered through a $0.45 \mu \mathrm{m}$ Millipore membrane and diluted to three times volume with water and then the sample solution was obtained and stored in a refrigerator to be used in the experiments.

\section{RESULTS AND DISCUSSION}

\section{Optimization of chemiluminescence conditions}

Effect of flow rate on chemiluminescence intensity: The chemiluminescence intensity increased with increasing the flow rate, but if the flow rate was too slow or too fast, a suitable chemiluminescence intensity could not be obtained. A flow rate of $25 \mathrm{rpm}$ for all solutions seemed to give the best results, which was therefore employed in all our measurements.

Effect of carrier flow: A number of carrier flows were tested at these selection conditions: ([2-keto-L-gulonic acid] $=2.0 \mathrm{mg} \mathrm{L}^{-1}$, [Rhodamine $\left.\mathrm{B}\right]=4.0 \times 10^{-4} \mathrm{~mol} \mathrm{~L}^{-1} ;\left[\mathrm{KMnO}_{4}\right]=$ $8.0 \times 10^{-4} \mathrm{~mol} \mathrm{~L}^{-1}$ ), those carrier flows included $\mathrm{HCl}, \mathrm{HNO}_{3}$, $\mathrm{H}_{2} \mathrm{SO}_{4}, \mathrm{H}_{3} \mathrm{PO}_{4}$ and acetic acid solutions. The experiments indicated that the chemiluminescence emission intensity were the most sensitive in $\mathrm{H}_{2} \mathrm{SO}_{4}$ solution. The influence of $\mathrm{H}_{2} \mathrm{SO}_{4}$ concentration over the range $1.0-2.0 \mathrm{~mol} \mathrm{~L}^{-1}$ on chemiluminescence emission intensities was investigated further and to our surprise, the use of $1.6 \mathrm{~mol} \mathrm{~L}^{-1} \mathrm{H}_{2} \mathrm{SO}_{4}$ solution as a carrier flow gave the best result; thus, we chose $1.6 \mathrm{~mol} \mathrm{~L}^{-1} \mathrm{H}_{2} \mathrm{SO}_{4}$ solution as the carrier flow.

Effect of $\mathrm{KMnO}_{4}$ concentration on chemiluminescence intensities: Fig. 3 showed the chemiluminescence intensities as a function of $\mathrm{KMnO}_{4}$ while keeping other reactants constant. Obviously, maximum chemiluminescence intensity was obtained when $\mathrm{KMnO}_{4}$ was at $8.0 \times 10^{-4} \mathrm{~mol} \mathrm{~L}^{-1}$. Above this concentration, chemiluminescence intensity decreased, may be due to the inner filter effect caused by absorption of the chemiluminescence emission by the high concentration of $\mathrm{KMnO}_{4}$. So the optimum concentration of $\mathrm{KMnO}_{4}$ was therefore chosen as $8.0 \times 10^{-4} \mathrm{~mol} \mathrm{~L}^{-1}$.

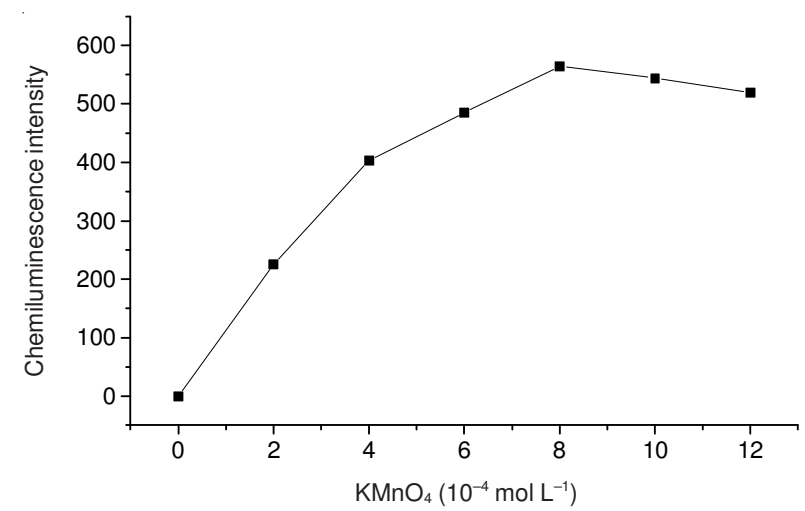

Fig. 3. Effect of $\mathrm{KMnO}_{4}$ concentration on chemiluminescence intensity. Conditions: $[\mathrm{PA}]=20 \mathrm{mg} \mathrm{L}^{-1}$, [Rhodamine $\left.\mathrm{B}\right]=4.0 \times 10^{-4} \mathrm{~mol} \mathrm{~L}^{-1}$ 
TABLE-1

DETERMINATION RESULTS OF 2-KETO-L-GULONIC ACID IN FERMENTED BROTH

\begin{tabular}{cccccc}
\hline Samples & Found $\left(\mathrm{mg} \mathrm{mL}^{-1}\right)$ & Added $\left(\mathrm{mg} \mathrm{mL}^{-1}\right)$ & Total found $\left(\mathrm{mg} \mathrm{mL}^{-1}\right)$ & Recovery $(\%)$ & HPLC method $\left(\mathrm{mg} \mathrm{mL}^{-1}\right)$ \\
\hline 1 & 71.6 & & 119.8 & 96.4 & 70.8 \\
2 & 69.5 & 50.0 & 121.4 & 103.8. & 68.6 \\
3 & 73.6 & & 120.6 & 94.0 & 73.1 \\
4 & 68.2 & & 116.6 & 96.8 & 68.7 \\
5 & 70.5 & & 118.3 & 95.6 & 69.2 \\
\hline
\end{tabular}

Effect of concentration of rhodamine-B on chemiluminescence intensities: The concentration of rhodamine B used in the reaction was also studied. The chemiluminescence emission intensity was enhanced with the rhodamine B concentration increasing while keeping other reactants constant. It was found that chemiluminescence intensities increased with the increase in rhodamine B concentration (Fig. 4). On the other hand, the base signal of chemiluminescence generated by the reaction between $\mathrm{KMnO}_{4}$ and rhodamine $\mathrm{B}$ also increased. In turn, the signal-to-noise ratio $(\mathrm{S} / \mathrm{N})$ increased as well. After an analysis of the $\mathrm{S} / \mathrm{N}$ ratio of the baseline and the sensitivity of the system, the best concentration of rhodamine B was $4 \times 10^{-4} \mathrm{~mol} \mathrm{~L}^{-1}$.

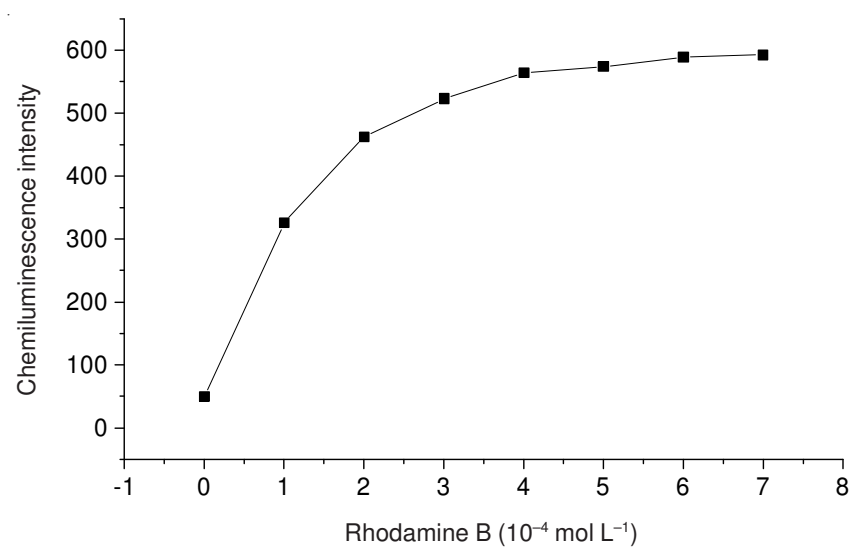

Fig. 4. Effect of rhodamine $B$ concentration on chemiluminescence intensity. Conditions: [2-keto-L-gulonic acid] $=2.0 \mathrm{mg} \mathrm{L}^{-1}$, $\left[\mathrm{KMnO}_{4}\right]=8.0 \times 10^{-4} \mathrm{~mol} \mathrm{~L}^{-1}$

Performance of the system for PA measurements: Under the optimum experimental conditions as above, the calibration curve of relative chemiluminescence intensity versus 2-keto-L-gulonic acid concentration over range $0.2-60 \mathrm{mg} \mathrm{L}^{-1}$ was obtained. A regression equation was obtained as:

$$
\mathrm{I}=14.35+315.24 \mathrm{c}\left(\mathrm{c}: \mathrm{mg} \mathrm{mL}^{-1} \mathrm{r}=0.9987\right)
$$

The detection limit $(3 \sigma)$ for the regression equation was $0.04 \mathrm{mg} \mathrm{L}^{-1}$ and the relative standard deviation $(\mathrm{RSD}, \mathrm{n}=11$ ) was $3.7 \%$ for $2 \mathrm{mg} \mathrm{L}^{-1}$ 2-keto-L-gulonic acid.

Study of interferences: Because 2-keto-D-gluconic acid and 2,5-diketo-D-gluconic acid might be accumulated simultaneously with 2-keto-L-gulonic acid in the fermentation broth during the course of preparing 2-keto-L-gulonic acid, the influences of 2-keto-D-gluconic acid and 2,5-diketo-D-gluconic acid on chemiluminescence intensities were mainly researched. The tolerable concentration ratios with respect to $2.0 \mathrm{mg} \mathrm{L}^{-1}$
2-keto-L-gulonic acid for interference at $5 \%$ level were examined. 20-fold 2,5-diketo-D-gluconic acid and 50-fold 2-keto-D-gluconic acid had almost no effect on the determination of 2-keto-L-gulonic acid. In order to assess the possible analytical application of the proposed chemiluminescence system to samples, the influences of some common inorganic ions and a couple of relevant organic compounds on chemiluminescence intensities were also investigated. 1000-fold $\mathrm{Ca}^{2+}$, $\mathrm{Mg}^{2+}, \mathrm{K}^{+}, \mathrm{Na}^{+}, \mathrm{Al}^{3+}, \mathrm{Zn}^{2+}, 500$-fold sodium tartrate, citrate, fructose, 100-fold glucose, L-glutamic acid, glycine had almost no effect on the determination of 2-keto-L-gulonic acid, respectively.

Sample analysis: The proposed method was applied to the determination of 2-keto-L-gulonic acid in five fermented broth. The results obtained by the method were shown in Table1. The measured concentrations by the proposed method were in good agreement with those obtained by HPLC ${ }^{8}$. To evaluate the validity of the proposed method, the recoveries for fermented broth samples were investigated. The recoveries were in the range of $94.0-103.8 \%$.

\section{Conclusion}

In this paper, a flow injection chemiluminescence detection method was developed for the determination of 2-keto-Lgulonic acid. Quantitative measurements of 2-keto-L-gulonic acid in fermented broth have been demonstrated. To the best of our knowledge, this is the first report on a chemiluminescence method that has been applied for the determination of 2-ketoL-gulonic acid in fermented broth. The presented chemiluminescence detection mode is simple, sensitive and efficient.

\section{REFERENCES}

1. L. Liu, K. Chen, J. Zhang, J. Liu and J. Chen, J. Biotechnol., 156, 182 (2011).

2. T. Reichstein, A. Gruessner and R. Oppenauer, Helv. Chim. Acta, 16, 1019 (1933).

3. J. Boundrant, Enzyme Microbiol. Technol., 12, 322 (1990).

4. G.L. Yin, Z.F. Ma, W.L. Dong, H. Lin and J. Ye, Acta Microbiol. Sin., 31, 198 (1991).

5. R.A. Lazarus and J.L. Seymour, Anal. Biochem., 157, 360 (1986).

6. O.K. Choi, C.G. Kim, Y.D. Kim, H. Kim and J.S. Jo, J. Chromatogr. A, 745, 249 (1996).

7. A.W. Anderson and G.T. Tsao, Biotcehnol. Bioeng., 26, 374 (1984).

8. Y.J. Hou and X.Y. Chen, Chin. J. Biotechnol., 15, 79 (2005).

9. S.H. Zhao, P.P. Zhang, X.H. Liang and D.L. Hua, J. Food Sci., 77, 102 (2012).

10. B.T. Zhang, L.X. Zhao and J.M. Lin, Talanta, 74, 1154 (2008).

11. P. Rolewski, A. Siger, M. Nogala-Kalucka and K. Polewski, Food Res. Int., 42, 165 (2009).

12. C.H. Qiao, C.S. Chen and F. Chen, Ind. Microbiol., 30, 9 (2000). 